\title{
The two-year incidence of hip osteoarthritis after arthroscopic hip surgery for femoroacetabular impingement syndrome
}

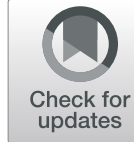

Daniel I. Rhon ${ }^{1,2^{*}}$ (D) Tina A. Greenlee ${ }^{3}$, Charles Dennis Sissel ${ }^{4}$ and Michael P. Reiman ${ }^{5}$

\begin{abstract}
Background: One of the reported goals of hip preservation surgery is to prevent or delay the onset of osteoarthritis. This includes arthroscopic surgery to manage Femoroacetabular Impingement (FAl) Syndrome. The purpose of this study was to describe the prevalence of clinically-diagnosed hip OA within 2 years after hip arthroscopy for FAl syndrome, and 2) determine which variables predict a clinical diagnosis of OA after arthroscopy.

Methods: Observational analysis of patients undergoing hip arthroscopy between 2004 and 2013, utilizing the Military Health System Data Repository. Individuals with prior cases of osteoarthritis were excluded. Presence of osteoarthritis was based on diagnostic codes rendered by a medical provider in patient medical records. Adjusted odds ratios $(95 \% \mathrm{Cl})$ for an osteoarthritis diagnosis were reported for relevant clinical and demographic variables.

Results: Of 1870 participants in this young cohort (mean age 32.2 years), 21.9\% ( $N=409)$ had a postoperative clinical diagnosis of hip osteoarthritis within 2 years. The 3 significant predictors in the final model were older age $(\mathrm{OR}=1.04 ; 95 \% \mathrm{Cl}=1.02,1.05)$, male sex $(\mathrm{OR}=1.31 ; 95 \% \mathrm{Cl}=1.04,1.65)$, and having undergone an additional hip surgery $(\mathrm{OR}=2.33 ; 95 \% \mathrm{Cl}=1.72,3.16)$. Military status and post-surgical complications were not risk factors.

Conclusion: A clinical diagnosis of hip osteoarthritis was found in approximately $22 \%$ of young patients undergoing hip arthroscopy in as little as 2 years. These rates may differ when using alternate criteria to define OA, such as radiographs, and likely underestimate the prevalence. A more comprehensive approach, considering various criteria to detect OA will likely be necessary to accurately identify the true rates. Females were at lower risk, while increasing age and multiple surgeries increased the risk for an OA diagnosis. OA onset still occurs after "hip preservation" surgery in a substantial number of individuals within 2 years. This should be considered when estimating rates of disease prevention after surgery. Prospective trials with sound methodology are needed to determine accurate rates and robust predictors of osteoarthritis onset after hip preservation surgery.
\end{abstract}

Keywords: Hip pain, Osteoarthritis, Arthroscopy, Femoroacetabular impingement syndrome

\section{Introduction}

Osteoarthritis (OA) of the knee and hip is a leading cause of disability worldwide, [1] and a primary cause of medical separation from the military [2]. Several crosssectional and longitudinal studies suggest that femoroacetabular impingement (FAI) syndrome is a precursor to future radiographic OA of the hip [3-6]. Well-designed

\footnotetext{
* Correspondence: daniel_rhon@baylor.edu

'Physical Performance Service Line, G 3/5/7, US Army Office of the Surgeon General, Falls Church, VA, USA

${ }^{2}$ Baylor University, Road, Bldg 2841, Suite 1301; JBSA Fort Sam Houston, Stanley, TX 3630, USA

Full list of author information is available at the end of the article
}

epidemiological studies that can adequately assess this relationship using other diagnostic criteria and in a younger adult population, are lacking [7]. Certain morphologic features of FAI Syndrome, particularly a large alpha angle, are suggested to predispose select patients to radiographic progression of hip OA $[8,9]$. Surgical correction is a common treatment approach utilized to alleviate the symptoms thought to arise when repetitive bony morphological abutment leads to labrum and cartilage damage [10-12]. This surgical correction is often called a 'hip preservation' procedure, considered to preserve the joint by preventing or at least slowing down

(c) The Author(s). 2019 Open Access This article is distributed under the terms of the Creative Commons Attribution 4.0 International License (http://creativecommons.org/licenses/by/4.0/), which permits unrestricted use, distribution, and reproduction in any medium, provided you give appropriate credit to the original author(s) and the source, provide a link to the Creative Commons license, and indicate if changes were made. The Creative Commons Public Domain Dedication waiver (http://creativecommons.org/publicdomain/zero/1.0/) applies to the data made available in this article, unless otherwise stated. 
the progression of OA in the femoroacetabular joint [13, 14]. It is unknown if this intervention alters the onset of OA beyond morphologically-normal controls [15].

The aim of delaying the onset and progression of hip OA has in part contributed to an exponential rise in the rate of arthroscopic surgery for FAI Syndrome, [16, 17] despite the lack of long-term outcomes, and inconclusive determination regarding whether surgical intervention can influence the natural history and progression of hip OA $[13,14]$. A recent systematic review reported weak evidence that surgical intervention may actually be associated with the structural progression of hip OA [18].

Determining the cost, impact on progression to degenerative joint disease, and benefit of surgery is needed to facilitate appropriate clinical decision-making [18]. A better understanding of the prevalence of OA after surgery in individuals without a pre-surgical diagnosis is necessary to improve estimates of disease onset and progression after surgery. Because radiographic evaluation of the hip may have limited reliability, [19] and due to the high rate of asymptomatic individuals with radiographic evidence of both FAI [20] and hip osteoarthritis, [21] expanding the scope of surveillance variables beyond radiographs is likely necessary to improve our understanding of this relationship. Therefore, the aims of this study were to: 1 ) describe the prevalence of a clinical diagnosis of hip OA within 2 years of hip arthroscopy for FAI Syndrome, and 2) determine which variables were significantly associated with a clinical diagnosis of OA after surgery.

\section{Methods}

\section{Study design}

The study was an observational cohort of patients seen within the U.S. Military Health System (MHS) that underwent arthroscopic hip surgery between 30 June 2004 and 1 July 2013.

\section{Setting}

Data were derived from the MHS Data Repository (MDR), which captures and tracks all medical visits for all Department of Defense (DoD) beneficiaries. This includes retired and active service members and their families. The MDR is the centralized data repository that captures, archives, validates, integrates and distributes Defense Health Agency (DHA) corporate healthcare data worldwide. Any medical visit, in a military or civilian setting, where the DoD insurance plan is the payer (covering $100 \%$ of armed services personnel and their dependents) is captured in the MDR.

\section{Participants}

We identified patients undergoing hip arthroscopy specifically for FAI Syndrome. Subjects under 18 or over 50 years of age were excluded, as this best represents the age range of adults that is most likely associated with FAI Syndrome (young to middle-age adults) [22]. It also represents the demographic age range of active duty service members. Because FAI Syndrome does not have its own International Classification of Diseases (ICD) diagnosis code, we identified procedures most often used to surgically treat this condition. Any subject with a recorded encounter including an arthroscopic surgical hip procedure, identified by Current Procedural Terminology (CPT) codes of 29914, 29915, 29916, or 29,862, was eligible for inclusion in the cohort. These codes identify the medical procedures rendered and are entered into individual electronic medical records. Individuals with loose body removal, diagnostic or exploratory arthroscopy codes alone (CPT codes 29860, 29861, 29863) were excluded. The codes were validated by surgeons performing a high volume of these procedures in the MHS, and these specific procedure codes have also been recommended for use in research [23]. All subjects with potential confounding diagnosis codes present prior to the surgery, which could otherwise rationalize the need for arthroscopic hip surgery, were excluded (hip avascular necrosis or infection, hip or pelvis fracture, a neoplasm or systemic arthropathy). Anyone with a prior diagnosis of OA was also excluded. Finally, all patients that were not eligible beneficiaries in the DoD health insurance and treatment plan for 12 months before and 24 months after surgery were also excluded to allow for a minimum of 2-year follow-up. Details of the extraction for the cohort have been published and are available [24].

\section{Reporting guidelines}

The REporting of studies Conducted using Observational Routinely collected health-Data (RECORD) statement, [25] an extension of the Strengthening of Reporting of Observational Studies in Epidemiology (STROBE) reporting guidelines, was used to guide reporting of this study. Ethical approval for the study was granted by the Brooke Army Medical Center Institutional Review Board.

\section{Data sources/measurement}

Person-level data for all outpatient and inpatient medical visits, both in military and civilian hospitals is captured in the MDR. The data from the MDR reflects a singlepayer system, compared to the more common thirdparty insurance-based system. MDR internally validates data through a system where all files initially enter MDR raw, and missing data elements are continuously run across multiple other data sources in order to impute missing variables. There are over 260 sources worldwide that feed into MDR. Raw data is validated against other 
databases internally within MDR, before being finalized, after 90 days from initial ingestion into MDR [24]. The MDR database is proprietary to the US DHA and requires a signed Data Sharing Agreement for access to any data. The methodology for data capture and rationale for use of variables has been explained previously in detail [24].

\section{Study variables}

Descriptive variables Patient characteristics included age, sex, military service status (military or civilian), socioeconomic status (categorized at the family unit level as military rank is associated with level of education and salary), location of surgery (military or civilian network hospital), and healthcare variables (utilization of rehabilitation and opioid pain medication). Postoperative opioid use in this cohort was defined as having $3+$ unique prescriptions in the 1 year following surgery, not including the immediate perioperative dose. In recognition that certain healthcare variables could also potentially influence outcomes, we also identified relevant surgery variables (procedure type), comorbidities present after surgery (insomnia, systemic arthropathy, substance abuse, mental health), complications (infection, avascular necrosis, fracture, heterotopic ossification), and additional hip surgeries. We compared the incidence of these events between both groups. Specific codes used to identify variables and relevance in individuals with musculoskeletal disorders have been published [24].

Outcome variables A diagnosis of hip osteoarthritis was identified by the presence of ICD-9 diagnostic codes rendered by a medical provided and documented in the patient's medical records within 24 months after surgery, and included 715.15, 715.25, 715.35, and 715.95. These codes were valid through June 2015, within the timeframe that this data was collected. This methodology has been utilized to identify incidence rates of osteoarthritis in this same population $[26,27]$.

Predictor variables For the final model we selected variables a priori that were known to have a relationship with osteoarthritis, to include age (risk is expected to increase with age), sex (higher incidence reported in females), [28] and active duty military status (higher incidence reported in active duty military) [29]. We also a priori identified two variables present after surgery with clinical rationale for a potential relationship with osteoarthritis: surgical complications and exposure to additional hip surgeries (e.g. revision, arthroplasty, etc.).

\section{Statistical approach}

We first reported the prevalence of an OA diagnosis found in this cohort within 2 years of surgery. Descriptive characteristics, including means, standard deviations and frequencies were calculated for 2 groups: 1) those with a diagnosis of OA and 2) those without. Descriptive data included patient level demographics, pre and postoperative variables (e.g. use of opioids or physical rehabilitation, medical comorbidities), and surgical variables (e.g. revisions, complications).

Given the nature of the dependent variable (OA diagnosis within 2 years), a binary logistic regression was performed to identify relevant predictor variables [30]. A logical clustering of two sets of variables based on clinical significance was employed using both a sequential and hierarchical approach. We chose variables with logical clinical significance. There were very small counts for individual complications, so they were bundled together, with $2.9 \%(n=55)$ having 1 or more complications, and $12.2 \%(n=228)$ undergoing an additional hip surgery. The measure of association between these two variables was relatively low ( $\mathrm{phi}=.071$ ), indicating poor likelihood of multicollinearity. For those who had complications, $74.5 \%(n=41)$ did not have additional surgery, hence both variables were included in the predictive model [31].

The first step included variables leading up to the surgical event (age, sex, and active duty military status) and the second step included variables occurring after the index surgery (complications and additional hip surgeries). This afforded the opportunity to assess to what extent the addition of post-surgical variables (when controlling for the set of pre-operative predictors) improved model fit. All parameter and pseudo $\mathrm{r}^{2}$ estimates were reported. The Hosmer-Lemeshow was used to assess model goodness of fit, [32] with non-significance preferred. All assumptions (distribution of residuals, leverage, influence, etc.) were closely examined. Adjusted Odds Ratios with 95\% confidence intervals were reported with a level of $\alpha=0.05$ set as significant. SPSS v24.0 (IBM Corp. Armonk, NY, USA) was used for all analyses.

\section{Results}

There were 1870 participants included in the final cohort (Fig. 1), with a mean age of 32.24 years $(\mathrm{SD}=8.09$, range from 18 to 50$)$ and $55.5 \%(n=1037)$ were males (Table 1). Within 2 years of undergoing hip arthroscopy, 409 individuals $(21.9 \%)$ had received a new clinical diagnosis of hip OA. Univariate comparison of clinical care variables in those with and without hip OA is reported in Table 2.

At the first step of the model (pre-surgery variables), the overall model was significant:, $p<0.001 ; 0 \%$ 
Arthroscopic Hip Surgeries between 2004 and 2013 for individuals between the ages of $18-50$ years,

\section{$\mathbf{N}=17,841$}

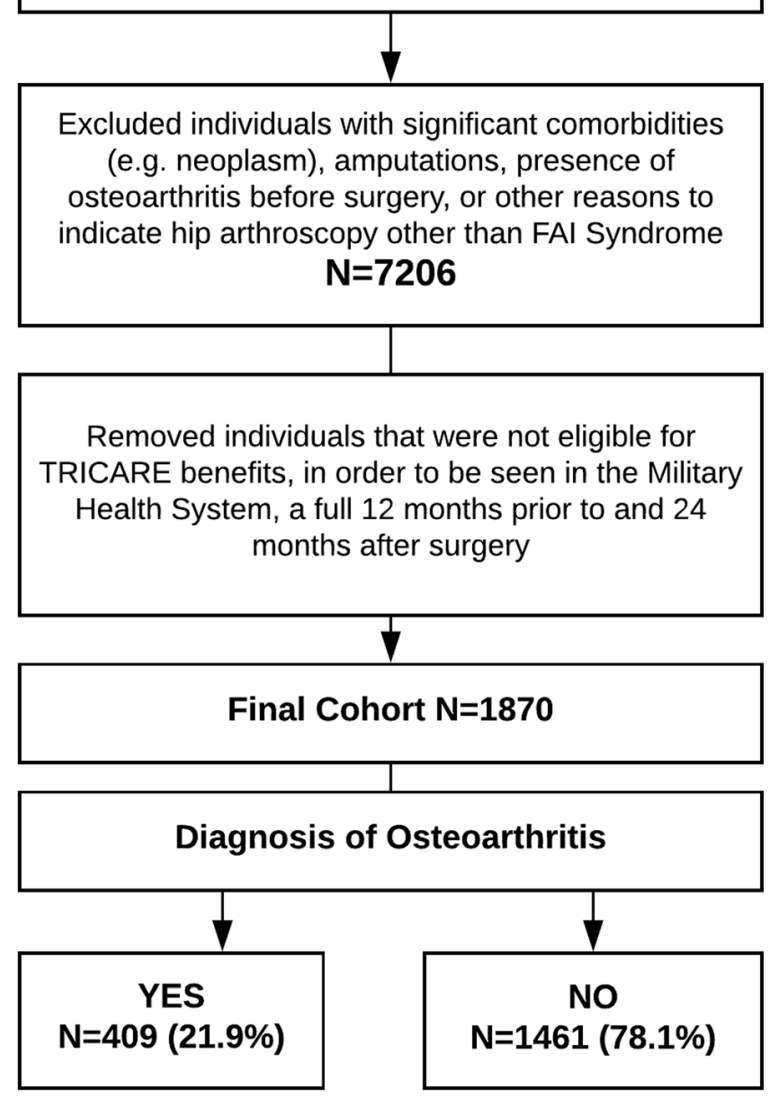

Fig. 1 Identification of cohort study flow

Sensitivity (Sn), 100\% specificity (Sp), 78.1\% accuracy. Age (higher) and sex (male) were significant predictors for an OA diagnosis (Table 3). At the second step of the model, adding the post-surgical variables improved the model $(p<0.001)$ and the overall model fit (i.e., all five predictors) was also significant $(\mathrm{p}<0.001)$. With the 5-predictor model (Table 3), there was $0.2 \%(\mathrm{Sn})$ and $99.7 \%(\mathrm{Sp})$ with an overall accuracy of $77.9 \%$. The following individual variables were significant: (1) age $(\mathrm{OR}=1.04 ; 95 \% \mathrm{CI}=1.02,1.05)$, (2) male sex $(\mathrm{OR}=$ $1.31 ; 95 \% \mathrm{CI}=1.04,1.65$ ), and (3) having undergone an additional hip surgery $(\mathrm{OR}=2.33 ; 95 \% \mathrm{CI}=1.72,3.16)$. Neither active duty military status nor complications were significant predictors of a new clinical diagnosis of OA (Table 3).

\section{Discussion}

The primary aim of this study was to identify the proportion of individuals that received a new clinical diagnosis of hip OA within 2 years of arthroscopic hip surgery, which in this cohort was $21.9 \%$. These findings suggest that a clinical diagnosis of OA can occur within as little as 2 years after arthroscopic hip-preservation surgery in younger adults without a pre-surgery diagnosis of OA. We also identified variables that predicted a clinical diagnosis of OA after surgery, which included age, sex, and having undergone an additional surgery. However, the predictors were not very strong, and only 1 of the 3 is potentially modifiable (additional surgeries). Caution is warranted with using these variables to predict OA after surgery. While associations between comorbidities and OA have been identified, for example mental health [33, 34] or diabetes, [35] there is no evidence to support their ability to predict onset of OA diagnosis and therefore these were not included in our model. Finally, other factors that were not captured within the data source utilized for this study may be of value and have stronger predictive capability (e.g. past history of injury, response to conservative treatment, radiographic baseline, characteristics of joint morphology, and specific prior physical demands based on military specialty or occupation).

The rate of $21.9 \%$ with a clinical diagnosis of OA is lower than reports of radiographic hip OA found within 24 months after hip arthroscopy (37\%), but in a slightly younger (mean age of 32 vs 37 years) and much larger cohort ( $N=1870$ vs 70) [6]. This may not be any different than the expected rate of radiographic OA findings in individuals with asymptomatic FAI, [15] albeit in older cohorts $\mathrm{f}$ (mean age 49.3 years). The incidence of OA among military service members in general, and especially of the hip, appears to be higher than the nonmilitary population [27, 36]. High-level occupationrelated physical demands, common in the military, and especially activities involving frequent and repetitive bending, squatting, kneeling, lifting, and climbing, have all been associated with hip OA [37, 38]. It is unknown if surgical intervention can influence these rates (i.e. reduce progression). However, our cohort included both active duty and civilian dependents, and military status was not a significant predictor of a clinical diagnosis of $\mathrm{OA}$ in the 2 years following hip arthroscopy.

Our findings suggest that females were at lower risk, while older age brought on greater risk for receiving a clinical diagnosis of hip OA after hip arthroscopy. Disease characteristics of FAI syndrome are reported to vary between males and females, [39] and this has the potential to influence onset and progression of OA. Another explanation for the lower rate in females is that greater loading of the hips increases the risk for developing OA, $[40,41]$ and during the period of surveillance in this study, females were not authorized in combat roles and therefore in positions with less load carriage requirements. In the 5th and 6th decade, rates of hip OA are 
Table 1 Demographics of Cohort at Baseline Comparing With and Without Hip Osteoarthritis

\begin{tabular}{|c|c|c|c|}
\hline & $\begin{array}{l}\text { Hip OA Diagnosis } \\
\text { YES } \\
409(21.9)\end{array}$ & $\begin{array}{l}\text { Hip OA Diagnosis } \\
\text { NO } \\
1461(78.1)\end{array}$ & $P$-value \\
\hline Female Sex & $151(36.9)$ & $682(46.7)$ & $<0.001^{*}$ \\
\hline Age Group - Mean (SD) & $34.1(7.9)$ & $31.7(8.1)$ & $<0.001^{*}$ \\
\hline $18-30-N(\%)$ & $143(35.0)$ & $702(48.0)$ & \\
\hline $31-40-N(\%)$ & $167(40.8)$ & $507(34.7)$ & \\
\hline $41-50-N(\%)$ & $99(24.2)$ & $252(17.2)$ & \\
\hline Beneficiary Category & & & 0.907 \\
\hline Active Duty & $270(66.0)$ & $993(68.0)$ & \\
\hline Guard-Reserve & $1(0.2)$ & $5(0.3)$ & \\
\hline Retired Service Member & $5(1.2)$ & $17(1.2)$ & \\
\hline Dependent & $94(23.0)$ & $326(22.3)$ & \\
\hline Other-unknown & $39(9.5)$ & $120(8.2)$ & \\
\hline \multicolumn{3}{|c|}{ Military Service (status of dependents based on service member) } & 0.786 \\
\hline Army & $176(43.0)$ & $657(45.0)$ & \\
\hline Air Force & $102(24.9)$ & $365(25.0)$ & \\
\hline Navy & 76 (18.6) & $229(15.7)$ & \\
\hline Marine Corps & $49(12.0)$ & $176(12.0)$ & \\
\hline Coast Guard & $5(1.2)$ & $25(1.7)$ & \\
\hline Other & $1(0.2)$ & $7(0.5)$ & \\
\hline Missing & 0 & $2(0.1)$ & \\
\hline \multicolumn{3}{|c|}{ Socioeconomic Status (status of dependents based on service member) } & $0.028^{*}$ \\
\hline Junior Enlisted & $84(20.5)$ & $388(26.6)$ & \\
\hline Senior Enlisted & $226(55.3)$ & $717(49.1)$ & \\
\hline Junior Officer & $42(10.3)$ & $190(13.0)$ & \\
\hline Senior Officer & $53(13.0)$ & $152(10.4)$ & \\
\hline Unknown & $4(1.0)$ & $14(1.0)$ & \\
\hline \multicolumn{3}{|l|}{ Location of Surgery } & $0.002^{*}$ \\
\hline Military Hospital & $184(45.0)$ & 783 (53.6) & \\
\hline Civilian Hospital & $225(55.0)$ & $678(46.4)$ & \\
\hline
\end{tabular}

Note: ${ }^{*} P<0.05 ; \mathrm{OA}=$ osteoarthritis; $\mathrm{N}(\%)$ unless otherwise noted

higher for women, but before then, they appear to be higher in men [42]. Specific to the relationship between hip OA and FAI syndrome, previous cohorts have had older participants (mean ages of 55.9 years, $[4,5] 62$ years, [43] 54 years, [44] 70.6 years, [45] 37 years for entire cohort - age of individuals with OA not reported, [6] and median age of 54 years [46]). The mean age in our cohort was 32 years, and less is known about younger patients. Further research is needed to clarify this relationship, especially in younger individuals.

The method for identifying osteoarthritis is also important to consider. Large epidemiological studies of $\mathrm{OA}$, such as the estimates of global burden of hip and knee osteoarthritis, [28] report utilizing 4 methods for the identification of osteoarthritis: 1) radiographic OA with symptoms, 2) radiographic OA regardless of symptoms, 3) self-report of OA, and 4) clinical diagnosis rendered by a medical professional. Estimates and comparisons are challenging, due to known disparities between these different methodologies. The majority of studies assessing the relationship between $\mathrm{OA}$ and FAI syndrome to date have used radiographic criteria [4-6, 43, 45-47]. We utilized a clinical diagnosis rendered by a medical provider. Given that only $\sim 25 \%$ of individuals with radiographic OA also have clinical symptoms, [28] it is likely that rates of OA would have been even higher in our cohort if radiographic criteria were utilized. Given all these findings, our methodology was more likely to have under rather than over-estimated the true rate of hip OA.

Having an additional surgery was also a factor that predicted a clinical diagnosis of $\mathrm{OA}$ in our model. 
Table 2 Univariate Comparison of Clinical Care Variables in those With and Without Hip Osteoarthritis

\begin{tabular}{|c|c|c|c|}
\hline & $\begin{array}{l}\text { Hip OA Diagnosis } \\
\text { YES } \\
\text { N (\%) - } 409(21.9)\end{array}$ & $\begin{array}{l}\text { Hip OA Diagnosis } \\
\text { NO } \\
\text { N (\%) - } 1461 \text { (78.1) }\end{array}$ & $P$-value \\
\hline \multicolumn{4}{|c|}{ Preoperative variables (PRESENT within 12 months prior to surgery) $N(\%)$} \\
\hline Hip-related Rehabilitation (at least 3 visits) & $191(46.7)$ & $659(45.1)$ & 0.575 \\
\hline Opioid Use & $180(44.0)$ & $581(39.8)$ & 0.125 \\
\hline \multicolumn{4}{|l|}{ Comorbidities } \\
\hline Insomnia & $35(8.6)$ & $130(8.9)$ & 0.845 \\
\hline Systemic Arthropathy & $5(1.2)$ & $29(2.0)$ & 0.404 \\
\hline Substance Abuse & $61(14.9)$ & $227(15.5)$ & 0.816 \\
\hline Mental Health & $98(24.0)$ & $274(18.8)$ & $0.021^{*}$ \\
\hline \multicolumn{4}{|l|}{ Operative variables } \\
\hline \multicolumn{4}{|l|}{ Surgical Procedures of Interest - N (\%) } \\
\hline Femoroplasty & $112(27.4)$ & $348(23.8)$ & 0.153 \\
\hline Acetabuloplasty & $75(18.3)$ & $241(16.5)$ & 0.412 \\
\hline Labral Repair & $98(24.0)$ & $395(27.0)$ & 0.228 \\
\hline \multicolumn{4}{|c|}{ Postoperative variables (present within 24 months after surgery) $N(\%)$} \\
\hline Hip-related Rehabilitation (at least 3 visits) & $353(86.3)$ & $1178(80.6)$ & $0.009 *$ \\
\hline Prescription Opioid Use & $320(78.2)$ & $1019(69.7)$ & $0.001^{*}$ \\
\hline \multicolumn{4}{|l|}{ Comorbidities } \\
\hline Insomnia & $35(8.6)$ & $116(7.9)$ & 0.758 \\
\hline Systemic Arthropathy & $20(4.9)$ & $59(4.0)$ & 0.486 \\
\hline Substance Abuse & $111(27.1)$ & $342(23.4)$ & 0.133 \\
\hline Mental Health & $185(45.2)$ & $515(35.2)$ & $<0.001^{*}$ \\
\hline \multicolumn{4}{|l|}{ Complications } \\
\hline Infection & $2(0.5)$ & $3(0.2)$ & 0.301 \\
\hline Avascular Necrosis & $5(1.2)$ & $3(0.2)$ & $0.015^{*}$ \\
\hline Fracture & $8(2.0)$ & $25(1.7)$ & 0.832 \\
\hline Heterotopic Ossification & $2(0.5)$ & $10(0.7)$ & 1.000 \\
\hline Additional Hip Surgery (e.g., revision) & $81(19.8)$ & $147(10.1)$ & $<0.001^{*}$ \\
\hline
\end{tabular}

Note: ${ }^{*} P<0.05, O A$ Osteoarthritis

Table 3 Adjusted Odds Ratios for Variables in Model Predicting Hip Osteoarthritis Diagnosis 24 months After Surgery

\begin{tabular}{|c|c|c|c|}
\hline & Odds Ratio & $95 \% \mathrm{Cl}$ & P-Value \\
\hline \multicolumn{4}{|c|}{ Step 1: Variables present at baseline Hosmer \& Lemeshow $p=0.445 ; \operatorname{Cox} R^{2}=0.018 ;$ Nagelkerke $R^{2}=0.028$} \\
\hline V1: Age & 1.037 & 1.023 to 1.052 & $<.001 *$ \\
\hline V2: Military Status (Active Duty) & 1.117 & 0.881 to 1.416 & 0.361 \\
\hline V3: Sex (male) & 1.305 & 1.035 to 1.645 & $0.025^{*}$ \\
\hline \multicolumn{4}{|c|}{ Step 2: Variables present after surgery Hosmer \& Lemeshow $p=0.826 ; \operatorname{Cox} R^{2}=0.033 ;$ Nagelkerke $R^{2}=0.051$} \\
\hline V4: Surgical Complications & 1.136 & 0.613 to 2.104 & 0.686 \\
\hline V5: Underwent an Additional Hip Surgery & 2.330 & 1.718 to 3.159 & $<.001 *$ \\
\hline
\end{tabular}

There was a significant effect when adding Step 2 variables to the model after Step $1\left(x^{2}(2)=28.48, p<.001\right)$. The parameter estimates are from the 2 nd step of variable entry (all 5 variables). $V$ Variable, $C$ Confidence Interval; ${ }^{*} \boldsymbol{P}<0.05$ 
Although no causality in these relationships can be implied, the fact that these individuals had an additional surgery suggests that the initial procedure was not satisfactory, and/or the extent of the pathology was more extensive. Additional surgeries also provided more interactions with the health system, and potentially more opportunities for an OA diagnosis to be rendered. Individuals undergoing additional surgeries also utilized more opioids and more physical rehabilitation, which may explain the higher utilization rates of each (opioids and physical therapy) in those with a diagnosis of OA.

Hip arthroscopy is a technically demanding procedure, $[48,49]$ with documented inconsistency in description of surgical indications, surgical technique and subject demographics $[50,51]$. The extent to which the variability of this treatment contributes to the difference in a OA diagnosis is unclear. If hip arthroscopy does indeed slow down progression of hip OA, then the experience of the surgeon or the procedure type could also potentially influence outcomes. For example, cam deformities are more strongly correlated to hip OA than pincer deformities, significantly predicting hip OA within 5 years. [47]. These variables were not available with this data set. In 2011 new CPT procedure codes, one each for cam and pincer lesions, as well as labral repair procedures codes became available, but system-wide adoption was likely not immediate and would have affected only the tail end of our cohort. The availability of this data for inclusion in our model would have been very insightful. The counter-argument is that surgical correction itself may be associated with structural progression of hip OA [18]. Arthroscopy can accelerate the progression of arthritis [52]. Hemarthrosis and even a single episode of intra-articular bleeding can lead to joint damage, adversely affect cartilage health, and potentially recapitulate and prolong the events initiated by the primary trauma $[53,54]$. Findings in asymptomatic individuals, including athletes with morphological changes and labral tears [20], along with reports that as many as $80 \%$ of non-surgical hips with morphology attributed to FAI Syndrome had not developed OA over a mean of 18.5 years after initial assessment, [15] suggest that some individuals will not develop hip OA, despite absence of surgical intervention. The lack of long-term, high quality studies supporting hip preservation surgery as a valid preventative procedure for hip OA are a necessary discussion point with patients if prevention of OA is one of the goals. Finally, improved methods for identifying early $\mathrm{OA}$ and measuring progression of the disease continue as significant gaps that prevent a clear understanding of the association between hip morphology and hip osteoarthritis onset.

These findings do not imply that OA is a caused by arthroscopic surgery, but rather that it is not uncommon to find a diagnosis rendered within as little as two years after surgery. The $21.9 \%$ incidence of an osteoarthritis diagnosis after surgery in this cohort after only 2 years is similar to rates of OA occurrence in patients with FAI Syndrome treated non-surgically over a mean of 18.5 years [15]. If our cohort were followed for 18.5 years, the incidence would likely be much higher. Prospective matched controls of younger individuals with and without FAI, and with and without surgery are needed to appropriately compare incidence rates and adequately determine whether the hip joint can be better-preserved over time through surgical intervention.

\section{Limitations}

There are several limitations. First of all, an OA diagnosis is based on a code in the patient medical record provided by a clinician. It is difficult to confirm what criteria was followed by the clinician to make the diagnosis. It likely included a combination of clinical and radiographic variables. Limited research exists regarding reliability and validity for case ascertainment using ICD diagnosis codes for osteoarthritis, and their value likely varies greatly depending on setting and type of diagnosis. For example, ICD codes are valid (95\% sensitivity; $96 \%$ specificity) for identifying patients with knee or hip replacement in the Veterans Health Administration system [55]. Although there can be false-positives, they tend to underestimate the rate in other conditions such as obesity ( $15.1 \%$ of true obesity rates were identified) [56] or psoriasis ( $81 \%$ valid case ascertainment) [57]. The sensitivity for identifying 32 different conditions using ICD-9 codes varied from 9.3 to $83.1 \%$ [58]. There is also no way to determine the severity of OA or its correlation with function/disability. Codes from medical records data have been used for surveillance of incidence rates in other studies within this population, [26, 27] although this methodology tends to underestimate the incidence rates of disease in general. This means that true rates of OA could be higher than $22 \%$. Patients in our cohort were also more likely to have symptomatic OA, as our definition required that patients sought out medical care and then received a diagnosis from a medical provider. While no clinical diagnosis of OA was rendered in the year prior to surgery, we cannot determine with certainty that OA did not exist prior to surgery. It is possible and likely that some of these patients had undetected or undiagnosed osteoarthritis prior to surgery. The specific genesis of OA is still an area of developing investigation, with a general lack of early indicators that are clinically relevant. Despite our best attempts to limit inclusion to only cases of arthroscopy specific to FAI syndrome, it is possible some of the arthroscopic cases were for other reasons. Occupational requirements vary across many various military 
positions, and therefore some service members could be more susceptible than others to higher and more repetitive loading of the hip. Unfortunately, we could not determine military occupational specialty from within MDR. However, this may have played less of a role, as there was no difference in clinical OA diagnosis rendered between military service members and civilians within our cohort. Finally, our cohort only included those that were still eligible TRICARE beneficiaries 2 years after surgery. Three times as many individuals that had surgery were not included in the cohort because they were not available for a minimum of 2 years after surgery (e.g. medical separation, retirement, end of enlistment, etc.). It is possible incidence rates could be different if all of these individuals were included. For those who were included, their healthcare utilization was only captured out to 2 years. Therefore, only diagnoses of OA within 2 years are represented. It is likely many more developed OA after 2 years. One study reported that hip OA could take more than 10 years to manifest [46].

\section{Conclusion}

A little over $20 \%$ of younger adults with no prior diagnosis of osteoarthritis that underwent hip arthroscopy for FAI syndrome received a clinical diagnosis of OA within 2 years of surgery. These rates may differ when using alternate criteria to define OA, such as radiographs. Estimating OA disease progression after hip arthroscopy for FAI syndrome in young adults is important and should take into consideration the various surveillance options. Each one has its downside, but a more comprehensive approach will likely be necessary to accurately identify the true rates of prevention of joint disease onset or disease progression that arthroscopic surgery is claimed to provide. Prospective trials with sound methodology are needed to determine accurate rates and predictors of osteoarthritis onset after hip preservation surgery.

\section{Abbreviations \\ CPT: Current Procedural Terminology; DHA: Defense Health Agency; DoD: Department of Defense; FAl: Femoroacetabular Impingement; IBM: International Business Machines; ICD: International Classification of Diseases; MDR: Military Health System Data Repository; MHS: Military Health System; OA: Osteoarthritis; RECORD: REporting of studies Conducted using Observational Routinely collected health-Data; Sn: Sensitivity; Sp: Specificity; SPSS: Statistical Package for Social Sciences; STROBE: Strengthening of Reporting of Observational Studies in Epidemiology}

\section{Acknowledgments}

We would like to thank the Geneva Foundation and Drs. Katie Dry, Rachel Mayhew, and Laurel Proulx for their assistance with the data preparation for analysis.

DISCLAIMER: The view(s) expressed herein are those of the author(s) and do not reflect the official policy or position of Brooke Army Medical Center, the U.S. Army Medical Department, the U.S. Army Office of the Surgeon General, the Department of the Army, Department of Defense, or the U.S.

Government.

\section{Authors' contributions}

DR; Grant funding recipient, study concept, data analysis and interpretation, manuscript writing and final approval. TG; Data analysis and interpretation, manuscript writing and final approval. DS; Data extraction from MDR and data cleaning, guidance on data interpretation, manuscript writing and final approval. MR: Concept, data interpretation, and manuscript writing and final approval.

\section{Funding}

This project was supported by an internal grant from the US Defense Health Agency [W911Qy-15-1-0016]. The played no role in the design, analysis, or interpretation of the results.

\section{Availability of data and materials}

Data from the Military Health System Data Repository (MDR) s proprietary to the US Defense Health Agency and can be made available after obtaining an approved Data Sharing Agreement from the DHA Privacy Board (further information can be found on health.mil).

\section{Ethics approval and consent to participate}

Ethics approval for this project was granted from the Institutional Review Board at Brooke Army Medical Center (C.2015.061d). Due to the retrospective nature of the study, waiver of consent was granted.

\section{Consent for publication}

Not applicable.

Competing interests

No authors have any competing interests to disclose.

\section{Author details}

${ }^{1}$ Physical Performance Service Line, G 3/5/7, US Army Office of the Surgeon General, Falls Church, VA, USA. ${ }^{2}$ Baylor University, Road, Bldg 2841, Suite 1301; JBSA Fort Sam Houston, Stanley, TX 3630, USA. ${ }^{3}$ Center for the Intrepid, Brooke Army Medical Center, 3551 Roger Brooke Drive, San Antonio, TX, USA ${ }^{4}$ Program Analysis \& Evaluation, US Army Medical Command, San Antonio, TX, USA. ${ }^{5}$ Department of Orthopaedic Surgery, Duke University Medical Center, Durham, NC, USA.

Received: 28 January 2019 Accepted: 20 May 2019

Published online: 01 June 2019

\section{References}

1. Cross M, Smith E, Hoy D, Nolte S, Ackerman I, Fransen M, et al. The global burden of hip and knee osteoarthritis: estimates from the global burden of disease 2010 study. Ann Rheum Dis. 2014;73:1323-30.

2. Patzkowski JC, Rivera JC, Ficke JR, Wenke JC. The changing face of disability in the US Army: the operation enduring freedom and operation Iraqi freedom effect. J Am Acad Orthop Surg. 2012;20(Suppl 1):S23-30.

3. Sankar WN, Nevitt M, Parvizi J, Felson DT, Agricola R, Leunig M. Femoroacetabular impingement: defining the condition and its role in the pathophysiology of osteoarthritis. J Am Acad Orthop Surg. 2013; 21(Suppl 1):S7-15.

4. Agricola $R$, Heijboer MP, Bierma-Zeinstra SMA, Verhaar JAN, Weinans $H_{\text {, }}$ Waarsing $\mathrm{JH}$. Cam impingement causes osteoarthritis of the hip: a nationwide prospective cohort study (CHECK). Ann Rheum Dis. 2013;72: 918-23

5. Agricola R, Heijboer MP, Roze RH, Reijman M, Bierma-Zeinstra SMA, Verhaar JAN, et al. Pincer deformity does not lead to osteoarthritis of the hip whereas acetabular dysplasia does: acetabular coverage and development of osteoarthritis in a nationwide prospective cohort study (CHECK). Osteoarthr Cartil. 2013;21:1514-21.

6. Kemp JL, Crossley KM, Agricola R, Geuskens F, van Middelkoop M. Radiographic hip osteoarthritis is prevalent, and is related to cam deformity 12-24 months post-hip arthroscopy. Int J Sports Phys Ther. 2018;13:177-84.

7. Agricola R, Weinans H. Femoroacetabular impingement: what is its link with osteoarthritis? Br J Sports Med. 2016:50:957-8.

8. Kowalczuk M, Yeung M, Simunovic N, Ayeni OR. Does Femoroacetabular impingement contribute to the development of hip osteoarthritis? A systematic review. Sports Med Arthrosc. 2015;23:174-9. 
9. Zeng W-N, Wang F-Y, Chen C, Zhang Y, Gong X-Y, Zhou K, et al. Investigation of association between hip morphology and prevalence of osteoarthritis. Sci Rep. 2016;6:23477.

10. Ito K, Minka-II M-A, Leunig M, Werlen S, Ganz R. Femoroacetabular impingement and the cam-effect. Bone Joint J. 2001;83-B:171-6.

11. Ganz R, Parvizi J, Beck M, Leunig M, Nötzli H, Siebenrock KA. Femoroacetabular impingement: a cause for osteoarthritis of the hip. Clin Orthop Relat Res. 2003:112-20.

12. Harris WH. Etiology of osteoarthritis of the hip. Clin Orthop Relat Res. 1986 20-33.

13. Nwachukwu BU, Rebolledo BJ, McCormick F, Rosas S, Harris JD, Kelly BT. Arthroscopic versus open treatment of Femoroacetabular impingement: a systematic review of medium- to long-term outcomes. Am J Sports Med. 2016:44:1062-8.

14. Sampson JD, Safran MR. Biomechanical implications of corrective surgery for FAl: an evidence-based review. Sports Med Arthrosc. 2015;23:169-73.

15. Hartofilakidis G, Bardakos NV, Babis GC, Georgiades G. An examination of the association between different morphotypes of femoroacetabular impingement in asymptomatic subjects and the development of osteoarthritis of the hip. J Bone Joint Surg Br. 2011;93:580-6.

16. Reiman MP, Thorborg K. Femoroacetabular impingement surgery: are we moving too fast and too far beyond the evidence? Br J Sports Med. 2015; 49:782-4.

17. Khan M, Ayeni OR, Madden K, Bedi A, Ranawat A, Kelly BT, et al. Femoroacetabular impingement: have we hit a global tipping point in diagnosis and treatment? Results from the InterNational Femoroacetabular impingement optimal care update survey (IN FOCUS). Arthroscopy. 2016;32: 779-87 e4.

18. Fairley J, Wang Y, Teichtahl AJ, Seneviwickrama M, Wluka AE, Brady SRE, et al. Management options for femoroacetabular impingement: a systematic review of symptom and structural outcomes. Osteoarthr Cartil. 2016;24: 1682-96.

19. Clohisy JC, Carlisle JC, Trousdale R, Kim Y-J, Beaule PE, Morgan P, et al. Radiographic evaluation of the hip has limited reliability. Clin Orthop Relat Res. 2009:467:666-75.

20. Frank JM, Harris JD, Erickson BJ, Slikker W 3rd, Bush-Joseph CA, Salata $\mathrm{MJ}$, et al. Prevalence of Femoroacetabular impingement imaging findings in asymptomatic volunteers: a systematic review. Arthroscopy. 2015;31:1199-204

21. Kim C, Nevitt MC, Niu J, Clancy MM, Lane NE, Link TM, et al. Association of hip pain with radiographic evidence of hip osteoarthritis: diagnostic test study. BMJ. 2015;351:h5983

22. Clohisy JC, Baca G, Beaulé PE, Kim Y-J, Larson CM, Millis MB, et al. Descriptive epidemiology of femoroacetabular impingement: a north American cohort of patients undergoing surgery. Am J Sports Med. 2013;41: 1348-56.

23. Truntzer JN, Shapiro LM, Hoppe DJ, Abrams GD, Safran MR. Hip arthroscopy in the United States: an update following coding changes in 2011. J Hip Preserv Surg. 2017:4:250-7.

24. Rhon DI, Clewley D, Young JL, Sissel CD, Cook CE. Leveraging healthcare utilization to explore outcomes from musculoskeletal disorders: methodology for defining relevant variables from a health services data repository. BMC Med Inform Decis Mak. 2018:18:10.

25. Benchimol El, Smeeth L, Guttmann A, Harron K, Moher D, Petersen I, et al. The REporting of studies conducted using observational routinely-collected health data (RECORD) statement. PLoS Med. 2015;12:e1001885.

26. Cameron KL, Hsiao MS, Owens BD, Burks R, Svoboda SJ. Incidence of physician-diagnosed osteoarthritis among active duty United States military service members. Arthritis Rheum. 2011;63:2974-82.

27. Scher DL, Belmont PJ Jr, Mountcastle S, Owens BD. The incidence of primary hip osteoarthritis in active duty US military service members. Arthritis Rheum. 2009:61:468-75.

28. Maillefert JF, Gueguen A, Monreal M, Nguyen M, Berdah L, Lequesne M, et al. Sex differences in hip osteoarthritis: results of a longitudinal study in 508 patients. Ann Rheum Dis. 2003;62:931-4.

29. Cameron KL, Driban JB, Svoboda SJ. Osteoarthritis and the tactical athlete: a systematic review. J Athl Train. 2016;51:952-61.

30. Peng C-YJ, Lee KL, Ingersoll GM. An introduction to logistic regression analysis and reporting. J Educ Res. 2002;96:3-14.

31. Rothman KJ, Greenland S, Lash TL. Modern Epidemiology: Lippincott Williams \& Wilkins; 2012.
32. Zhang Z. Model building strategy for logistic regression: purposeful selection. Ann Transl Med. 2016:4:111.

33. Stubbs B, Hurley M, Smith $T$. What are the factors that influence physical activity participation in adults with knee and hip osteoarthritis? A systematic review of physical activity correlates. Clin Rehabil. 2015:29:80-94

34. Stubbs B, Veronese N, Vancampfort D, Thompson T, Kohler C, Schofield P, et al. Lifetime self-reported arthritis is associated with elevated levels of mental health burden: a multi-national cross sectional study across 46 low- and middle-income countries. Sci Rep. 2017;7:7138.

35. Piva SR, Susko AM, Khoja SS, Josbeno DA, Fitzgerald GK, Toledo FGS. Links between osteoarthritis and diabetes. implications for management from a physical activity perspective Clin Geriatr Med. 2015;31:67-87 viii.

36. Showery JE, Kusnezov NA, Dunn JC, Bader JO, Belmont PJ Jr, Waterman $B R$. The Rising Incidence of Degenerative and Posttraumatic Osteoarthritis of the Knee in the United States Military. J Arthroplasty. 2016:31:2108-14

37. Allen KD, Chen J-C, Callahan LF, Golightly YM, Helmick CG, Renner JB, et al. Associations of occupational tasks with knee and hip osteoarthritis: the Johnston County osteoarthritis project. J Rheumatol. 2010;37:842-50.

38. Lau EC, Cooper C, Lam D, Chan VN, Tsang KK, Sham A. Factors associated with osteoarthritis of the hip and knee in Hong Kong Chinese: obesity, joint injury, and occupational activities. Am J Epidemiol. 2000;152:855-62

39. Nepple JJ, Riggs CN, Ross JR, Clohisy JC. Clinical presentation and disease characteristics of femoroacetabular impingement are sex-dependent. J Bone Joint Surg Am. 2014;96:1683-9.

40. Plotnikoff R, Karunamuni N, Lytvyak E, Penfold C, Schopflocher D, Imayama I, et al. Osteoarthritis prevalence and modifiable factors: a population study. BMC Public Health. 2015;15:1195.

41. Buckwalter JA, Anderson DD, Brown TD, Tochigi Y, Martin JA. The roles of mechanical stresses in the pathogenesis of osteoarthritis: implications for treatment of joint injuries. Cartilage. 2013:4:286-94.

42. Neogi T, Zhang Y. Epidemiology of osteoarthritis. Rheum Dis Clin N Am. 2013;39:1-19.

43. Nelson AE, Stiller JL, Shi XA, Leyland KM, Renner JB, Schwartz TA, et al. Measures of hip morphology are related to development of worsening radiographic hip osteoarthritis over 6 to 13 year follow-up: the Johnston County osteoarthritis project. Osteoarthr Cartil. 2016:24:443-50.

44. Nicholls AS, Kiran A, Pollard TCB, Hart DJ, Arden CPA, Spector T, et al. The association between hip morphology parameters and nineteen-year risk of end-stage osteoarthritis of the hip: a nested case-control study. Arthritis Rheum. 2011;63:3392-400

45. Saberi Hosnijeh F, Zuiderwijk ME, Versteeg M, Smeele HTW, Hofman A, Uitterlinden AG, et al. Cam deformity and acetabular dysplasia as risk factors for HIP osteoarthritis: BONY DEFORMITIES AS RISK FACTORS FOR HIP OA. Arthritis \& Rheumatology. 2017;69:86-93.

46. Bardakos NV, Villar RN. Predictors of progression of osteoarthritis in femoroacetabular impingement: a radiological study with a minimum of ten years follow-up. J Bone Joint Surg Br. 2009;91:162-9.

47. Wyles CC, Norambuena GA, Howe BM, Larson DR, Levy BA, Yuan BJ, et al. Cam deformities and limited hip range of motion are associated with early osteoarthritic changes in adolescent athletes: a prospective matched cohort study. Am J Sports Med. 2017:45:3036-43.

48. Hoppe DJ, de Sa D, Simunovic N, Bhandari M, Safran MR, Larson CM, et al. The learning curve for hip arthroscopy: a systematic review. Arthroscopy. 2014;30:389-97.

49. Mehta N, Chamberlin P, Marx RG, Hidaka C, Ge Y, Nawabi DH, et al. Defining the learning curve for hip arthroscopy: a threshold analysis of the volumeoutcomes relationship. Am J Sports Med 2018:"363546517749219.

50. Peters S, Laing A, Emerson C, Mutchler K, Joyce T, Thorborg K, et al. Surgical criteria for femoroacetabular impingement syndrome: a scoping review. $\mathrm{Br} J$ Sports Med. 2017:51:1605-10.

51. Erickson BJ, Cvetanovich GL, Frank RM, Bhatia S, Bush-Joseph CA, Nho SJ, et al. International trends in arthroscopic hip preservation surgery-are we treating the same patient? J Hip Preserv Surg. 2015;2:28-41.

52. Parvizi J, Bican O, Bender B, Mortazavi SMJ, Purtill JJ, Erickson J, et al. Arthroscopy for labral tears in patients with developmental dysplasia of the hip: a cautionary note. J Arthroplast. 2009;24(6 Suppl):110-3.

53. Roosendaal $G$, Vianen ME, Wenting MJ, van Rinsum $A C$, van den Berg $H M$, Lafeber FP, et al. Iron deposits and catabolic properties of synovial tissue from patients with haemophilia. J Bone Joint Surg Br. 1998;80:540-5. 
54. Lotz MK, Kraus VB. New developments in osteoarthritis. Posttraumatic osteoarthritis: pathogenesis and pharmacological treatment options. Arthritis Res Ther. 2010;12:211.

55. Singh JA, Ayub S. Accuracy of VA databases for diagnoses of knee replacement and hip replacement. Osteoarthr Cartil. 2010;18:1639-42.

56. Mocarski M, Tian Y, Smolarz BG, McAna J, Crawford A. Use of International classification of diseases, ninth revision codes for obesity: trends in the United States from an electronic health record-derived database. Popul Health Manag. 2018;21:222-30.

57. Löfvendahl S, Theander E, Svensson A, Carlsson KS, Englund M, Petersson IF. Validity of diagnostic codes and prevalence of physician-diagnosed psoriasis and psoriatic arthritis in southern Sweden--a population-based register study. PLoS One. 2014;9:e98024.

58. Quan H, Li B, Saunders LD, Parsons GA, Nilsson Cl, Alibhai A, et al. Assessing validity of ICD-9-CM and ICD-10 administrative data in recording clinical conditions in a unique dually coded database. Health Serv Res. 2008;43: $1424-41$.

\section{Publisher's Note}

Springer Nature remains neutral with regard to jurisdictional claims in published maps and institutional affiliations.

Ready to submit your research? Choose BMC and benefit from:

- fast, convenient online submission

- thorough peer review by experienced researchers in your field

- rapid publication on acceptance

- support for research data, including large and complex data types

- gold Open Access which fosters wider collaboration and increased citations

- maximum visibility for your research: over $100 \mathrm{M}$ website views per year

At $\mathrm{BMC}$, research is always in progress.

Learn more biomedcentral.com/submissions 